\title{
РАЗВИТИЕ ЭЛЕКТРОННЫХ СИСТЕМ ОПЛАТЫ ПРОЕЗДА В ГОРОДСКОМ ПАССАЖИРСКОМ ТРАНСПОРТЕ ОБЩЕГО ПОЛЬЗОВАНИЯ
}

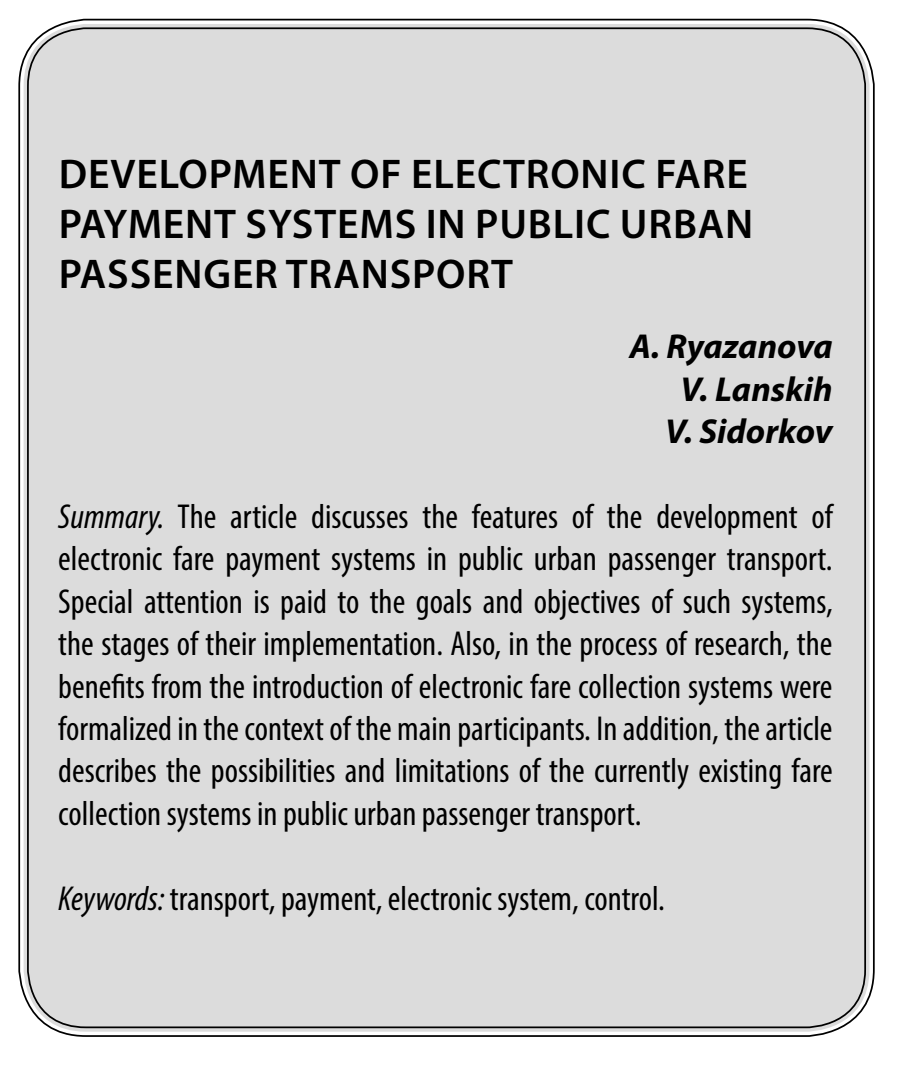

П рогресс, который был достигнут за последние десятилетия в различных аспектах вычислительной техники привел к значительному расширению сферы применения компьютеров. Неотъемлемой частью современного социума является разнообразные системы сбора, обработки и хранения информации, которые представляют собой обязательную часть научно-технической революции. Эти кардинальные сдвиги в свою очередь способствовали распространению безналичных систем расчетов, что повлекло за собой целый ряд трансформаций, которые повлияли на экономические, технико-технологические и программно-аппаратные изменения многих сфер мирового хозяйства [1]. Активное распространение в различных сферах экономических отношений получили бесконтактные технологии, в том числе банковские карты, мобильные телефоны с технологией NFC, различные устройства-носители.

Эти трансформационные сдвиги привели к тому, что в городском пассажирском транспорте общего пользования (трамвай, троллейбус, метрополитен), являюще-

\author{
Рязанова Анна Владимировна \\ Старший преподаватель, Тихоокеанский \\ государственный университет, г. Хабаровск \\ 89241016159@yandex.ru \\ Ланских Виктория Владимировна \\ Старший преподаватель, Тихоокеанский \\ государственный университет, г. Хабаровск \\ Ivik9@mail.ru \\ Сидорков Владимир Владимирович \\ Дочент, Тихоокеанский государственный \\ университет, г. Хабаровск \\ sidorkov@pnu.edu.ru
}

Аннотация. В статье рассмотрены особенности развития электронных систем оплаты проезда в городском пассажирском транспорте общего пользования. Отдельное внимание уделено целям и задачам таких систем, этапам их внедрения. Также в процессе исследования формализованы выгоды от использования электронных систем оплаты проезда в разрезе основных участников. Кроме того, описаны возможности и ограничения, существующих на сегодняшний день систем оплаты проезда в городском пассажирском транспорте общего пользования.

Ключевые слова: транспорт, оплата, электронная система, контроль.

гося одним из наиболее значимых звеньев народного хозяйства, которое обеспечивает передвижение основной массы людей на свои рабочие места, постепенно осуществляется внедрение электронных систем оплаты проезда.

В большинстве развитых стран мира уже успешно работают системы единого электронного билета для оплаты проезда в городском пассажирском общественном транспорте, которые включают в себя механизмы оплаты через электронные системы, системы контроля оплаты проезда и т.д. В некоторых странах они интегрированы на всей территории, используют единую систему оплаты для всех видов транспорта (по большей части дифференцированную по количеству купленных поездок или дальности передвижения), позволяют пассажиру оплатить услугу проще, быстрее и удобнее, а транспортной компании - увеличить прибыль за счет повышения точности учета оплаты проезда, отслеживания пассажиропотока и наглядности для корректировки маршрутной сети и загруженности существующих маршрутов. 
Однако с появлением новых технологий, в контексте стремительного внедрения цифровых инноваций, развитие единой системы оплаты проезда в городском пассажирском транспорте общего пользования не стоит на месте. Не подлежит сомнению тот факт, что используемые на сегодняшний день технологии должны отвечать не только современным требованиям, но и иметь перспективу совершенствования. Устаревшие и неэффективные методы планирования транспортных перемещений населения, несовершенные системы оплаты проезда и отсутствие четкого учета предоставленных транспортных услуг ведут к дальнейшей деградации и упадку транспортной инфраструктуры, которая является залогом успешного развития экономики любого уровня.

Данные обстоятельства обуславливают выбор темы данной статьи, а также подтверждает ее теоретическую и практическую значимость.

Проблематике совершенствования контроля оплаты в городском пассажирском транспорте посвящено много работ зарубежных ученых к числу которых можно отнести: Borges Ricard, Yoon M.G.; Yoon D.Y.; Yang T.W.; Zhan Shuguang; Cascetta Ennio; Truong Dothang.

С развитием электронных систем ряд ученых активно разрабатывают вопросы бесконтактной оплаты проезда в смежных секторах - на городском и пригородном транспорте. В данном направлении активно работают Dydkowski Grzegorz, Goto K.; Kambayashi Y.; Halevy A.Y.; Ives Z.G.; Doan A.

Из числа отечественных авторов, которые в своих работах анализируют особенности создания и внедрения единого электронного билета в России, который является одним из эффективных методов автоматизированного учета пассажирских перевозок, можно отметить Фадеева А.И., Алхуссейни С., Малышева М.И., Брагинского С.А., Ивахненко А.А.

Однако, несмотря на имеющиеся научные исследования и наработки на сегодняшний день все еще остается ряд нерешенных проблем, которые тормозят прогресс науки в данной области, в частности, открытыми остаются проблемы интеграции систем электронной оплаты проезда, которые имеют локальный и региональный характер. Также в дополнительном обосновании нуждаются вопросы обосновании стратегий и методов моделирования автоматизированных систем оплаты проезда в городском общественном транспорте и стратегического управления процессом их внедрения.

Таким образом, с учетом вышеизложенного, цель статьи заключается в исследовании особенностей и пер- спектив развития электронных систем оплаты проезда в городском пассажирском транспорте общего пользования.

Система транспортных услуг имеет все признаки открытой макросистемы с определяющим внешним влиянием и возможностью самостоятельной корректировки и саморазвития как в сторону расширения, так и в сторону перехода на другие уровни с учетом внешних факторов воздействия [2]. С учетом этого, можно отметить, что эффективное функционирование электронных систем оплаты проезда в городском пассажирском транспорте общего пользования должно быть обеспечено работой трех согласованных и взаимно интегрированных системными составляющих, а именно технико-технологической, экономической и юридической.

В свою очередь целями и задачами электронных систем оплаты проезда в городском пассажирском транспорте общего пользования являются:

- получение достоверных аналитических данных о реальных потоках пассажиров на транспорте;

- внедрение автоматизированных систем оплаты проезда организация перехода к безналичной плате за проезд;

- повышение объема поступающих от платы за проезд денежных средств, за счет уменьшения части неучтенной выручки;

- использование системы наценки в случае покупки билета за наличные денежные средства непосредственно в общественном транспорте с целью стимулирования использования электронных средств оплаты;

- снижение воздействия человеческого фактора на процесс оплаты проезда;

- использование цифровых технологий и инноваций, которые позволят обеспечить персонифицированный учет перевозок льготных категорий;

- автоматизация расчетов между перевозчиками и органами власти, касающиеся возмещения средств за перевозку льготников;

- снижение затрат транспортных предприятий;

- обеспечение точного исчисления расходов бюджетов для оптимизации размера субсидий, выделяемых на перевозку льготников.

В таблице 1 наглядно отражены все участники системы перевозки пассажиров городским транспортом и их выгоды от внедрения электронных систем оплаты проезда.

Внедрение автоматизированной системы оплаты проезда предполагает прохождение нескольких этапов (рис. 1). 
Таблица 1. Выгоды от внедрения электронных систем оплаты проезда в разрезе основных участников

\begin{tabular}{|l|l|}
$\begin{array}{l}\text { Заинтересованные } \\
\text { стороны }\end{array}$ & Выгоды \\
Органы власти & $\begin{array}{l}\text { увеличение количества граждан, которые пользуются общественным транспортом; } \\
\text { установление низких цен и простых тарифов; } \\
\text { балансировка расходов и поощрение социальной интеграции; } \\
\text { минимизация государственных субсидий или финансовой компенсации; } \\
\text { создание беспрепятственных поездок в сетях общественного транспорта; } \\
\text { унификация билетов; } \\
\text { источник новых маркетинговых данных; }\end{array}$ \\
\hline Оператор & $\begin{array}{l}\text { покрытие расходов и максимизация прибыли; } \\
\text { оптимизация потока наличност; } \\
\text { создание привлекательной системы общественного транспорта; } \\
\text { снижение стоимости продажи билетов и количества мошенничеств; } \\
\text { уменьшение времени посадки; }\end{array}$ \\
\hline Пассажир & $\begin{array}{l}\text { снижение транспортной стоимости; } \\
\text { проезд в комфортныхусловиях; } \\
\text { простые способы пополнения или обновления проездных документов. }\end{array}$ \\
\hline
\end{tabular}

І Этап
для категории льготников

Рис. 1. Этапы внедрения автоматизированной системы оплаты проезда

На первом этапе внедряется кондукторная система с автоматизацией оплаты проезда для льготных категорий граждан. Продолжительность этого этапа составляет 1 год. За этот год нужно обеспечить всех льготных пассажиров карточками и наладить бесперебойную работу системы. На втором этапе происходит выпуск карт оплаты проезда для всех категорий граждан. Этот этап занимает 1-2 года. На третьем этапе осуществляется замена переносных терминалов кондуктора стационарными терминалами. Функция кондуктора становится наблюдательной. Третий этап происходит за 2-3 месяца интенсивной работы. На четвертом этапе происходит освобождение кондукторов и наращивание штата контролеров. Выполнение четвертого этапа возможно только после $50 \%$ охвата картами всех категорий населения.

На сегодняшний день в мире разработан широкий спектр систем автоматизированной системы оплаты проезда, с использованием различных технологий, которые обуславливают их возможности и недостатки (см. табл. 2).

Международные исследования свидетельствуют о том, что разные по возрасту слои населения склонны использовать различные средства оплаты. Так, молодежь в основном предпочитает платить с помощью QR-кодов с мобильных устройств, люди среднего возраста преимущественно используют пластиковые транспортные карты, а старшие по возрасту - привычные для них бумажные билеты или жетоны [3]. Однако, независимо от способа оплаты используемые средства должны быть с достаточным уровнем защиты от подделок и с высоким уровнем устойчивости к поломкам (за исключением бумажных носителей). Способы пополнения должны быть надежными, разнообразными и понятными, а сам процесс пополнения гибким и непродолжительным по времени. 
Таблица 2. Сравнение нескольких технологической платформ

\begin{tabular}{|c|c|c|c|c|c|c|c|}
\hline 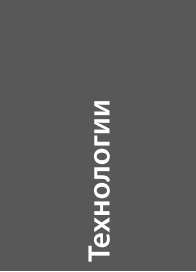 & 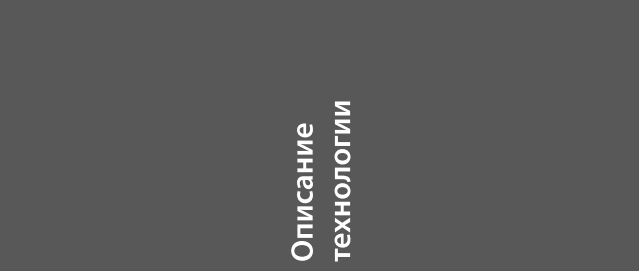 & 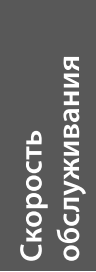 & 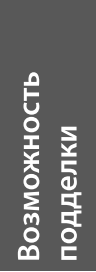 & 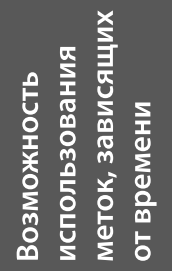 & 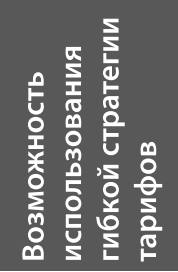 & 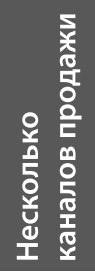 & 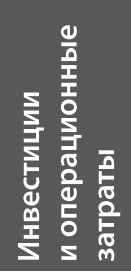 \\
\hline $\begin{array}{l}\text { Наличные } \\
\text { деньги }\end{array}$ & $\begin{array}{l}\text { Пассажир платит водителю при входе } \\
\text { в автобус / трамвай }\end{array}$ & & & & & & \\
\hline Жетоны & $\begin{array}{l}\text { Металлический жетон только для } \\
\text { использования в транспорте. Пассажир платит } \\
\text { при входе }\end{array}$ & & & & & & \\
\hline $\begin{array}{l}\text { Бумажный } \\
\text { билет }\end{array}$ & $\begin{array}{l}\text { Пассажир использует бумажный билет } \\
\text { на поездку }\end{array}$ & & & & & & \\
\hline $\begin{array}{l}\text { Магнитная } \\
\text { полоса }\end{array}$ & $\begin{array}{l}\text { Информация о поездке закодирована } \\
\text { на магнитной полосе на обратной стороне } \\
\text { билета, как на кредитной карте } \\
\end{array}$ & & & & & & \\
\hline $\begin{array}{l}\text { Транспортная } \\
\text { смарт-карта }\end{array}$ & $\begin{array}{l}\text { Микросхема памяти, встроенная в пластиковую } \\
\text { карту с контактным интерфейсом, по которому } \\
\text { проходят билеты пассажиров. Предъявив } \\
\text { карту к считывателю, пассажир может войти } \\
\text { в систему транспорта }\end{array}$ & & & & & & \\
\hline 2D штрих-код & $\begin{array}{l}\text { Двухмерный штрих-код либо распечатывается } \\
\text { пассажиром перед поездкой, либо } \\
\text { переносится на мобильное устройство, как } \\
\text { билеты на самолет }\end{array}$ & & & & & & \\
\hline $\begin{array}{l}\text { Бесконтакт- } \\
\text { ная платеж- } \\
\text { ная карточка }\end{array}$ & $\begin{array}{l}\text { Используется банковская карточка, выданная } \\
\text { для оплаты проезда пассажира, который } \\
\text { подключается к транспортной системе. }\end{array}$ & & & & & & \\
\hline $\begin{array}{l}\text { Мобильный } \\
\text { девайс }\end{array}$ & $\begin{array}{l}\text { Мобильное устройство используется для } \\
\text { хранения билета, который отображается } \\
\text { визуально или с помощью двухмерного штрих- } \\
\text { кода }\end{array}$ & & & & & & \\
\hline $\begin{array}{l}\text { Идентифи- } \\
\text { цированный } \\
\text { токен }\end{array}$ & $\begin{array}{l}\text { Пассажир представляет идентифицированный } \\
\text { токен, т.е. бесконтактную банковскую } \\
\text { карту, карту PIV, идентификационную карту } \\
\text { или подобную банковскую карту, которая } \\
\text { производит расчет оплаты }\end{array}$ & & & & & & \\
\hline $\begin{array}{l}\text { Устройство } \\
\text { беспрово- } \\
\text { дной переда- } \\
\text { чи данных }\end{array}$ & $\begin{array}{l}\text { Эта функциональность позволяет мобильному } \\
\text { телефону подключаться в той же сети, что } \\
\text { и транспортная карта без непосредственного } \\
\text { контакта. }\end{array}$ & & & & & & \\
\hline $\begin{array}{l}\text { Биометриче- } \\
\text { ские устрой- } \\
\text { ства }\end{array}$ & $\begin{array}{l}\text { В транспортной сфере пока находится } \\
\text { в зачаточном состоянии, предполагает } \\
\text { использование биометрических символов для } \\
\text { обозначения права на поездку }\end{array}$ & & & & & & \\
\hline
\end{tabular}

Таким образом, подводя итоги отметим, что электронные системы оплаты проезда в городском пассажирском транспорте общего пользования имеют большие перспективы. Однако они требуют достаточно сложной реализации перехода, использования специализированных программных и технических составляющих, при этом, необходимо акцентировать внимание на том, что внедрение электронной системы оплаты не должно повлечь за собой повышение расходов транспортных предприятий и увеличение стоимости проезда. Глобальная цель данной системы - учет всех пассажиров и отдельно льготников, отслеживание пассажиропотока, улучшения качества маршрутной сети городов и как результат - повышение привлекательности городского пассажирского транспорта общего пользования среди пассажиров. 


\section{ЛИТЕРАТУРА}

1. Постолит А.В. Тенденции развития транспортных платежных систем в зарубежных странах // Грузовик. 2019. № 10. С. $21-31$.

2. Upendra Reddy, C. Bus Ticket System for Public Transport Using QR Code // IOP conference series. Materials science and engineering. 2019. Volume 590; 33 198-214.

3. Šurdonja, Sanja Smart mobility solutions - necessary precondition for a well-functioning smart city // Transportation research procedia. 2020. Volume 45; pp 604-611.

(c) Рязанова Анна Владимировна (89241016159@yandex.ru ),

Ланских Виктория Владимировна ( Ivik9@mail.ru), Сидорков Владимир Владимирович ( sidorkov@pnu.edu.ru).

Журнал «Современная наука: актуальные проблемы теории и практики»

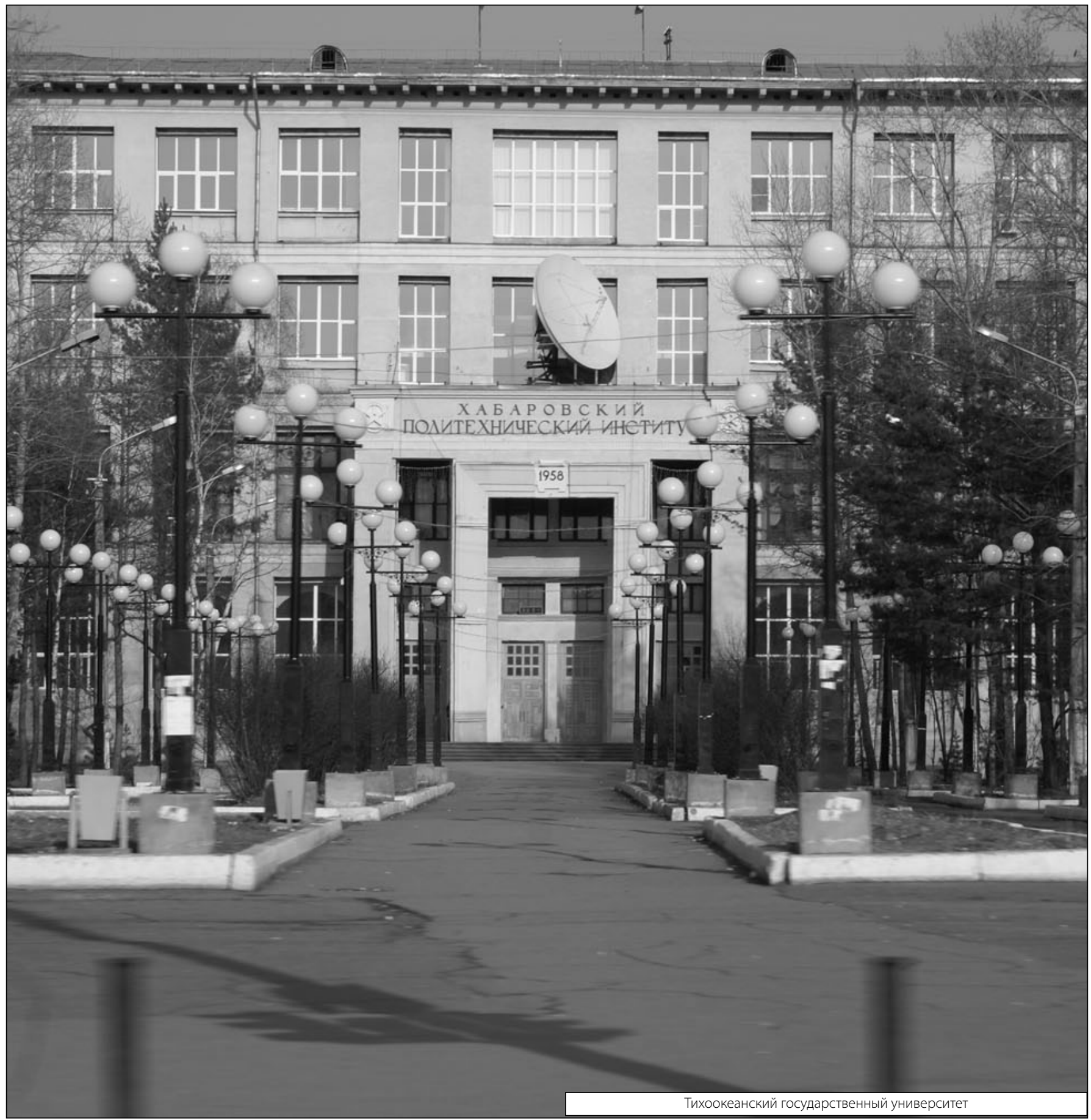

